\title{
The spatial structure of regional logistics and influencing factors: an empirical analysis based on Sichuan Province, China
}

\author{
Meng Ye ( $\nabla 2017225020025 @ s t u . s c u . e d u . c n$ ) \\ Sichuan University https://orcid.org/0000-0002-9913-8370 \\ Wenjie Mao \\ Sichuan University \\ yaqi wang \\ Sichuan University
}

\section{Research Article}

Keywords: Regional logistics structure, Social network analysis, QAP analysis, Influencing factors

Posted Date: February 17th, 2022

DOI: https://doi.org/10.21203/rs.3.rs-1213810/v1

License: @ (i) This work is licensed under a Creative Commons Attribution 4.0 International License. Read Full License 


\section{Abstract}

The purpose of the paper is to find the influencing factors of the regional logistics spatial structure and propose suggestions to stimulate the vitality of the regional economy. Taking Sichuan Province as an example, this paper uses principal component analysis to improve the gravity model to measure the logistics gravity between cities. Use the social network analysis method to calculate the regional logistics spatial network correlation structure in Sichuan Province from 2010 to 2018. The QAP analysis method is then used to identify the factors that affect the development level of regional logistics specialization. The research results show that the logistics relationship between cities has become closer from 2010 to 2018, but network resilience needs to be strengthened. The division of blocks is the same as that of the five major economic regions of Sichuan Province, but there is an urgent need to enhance cooperation between plates. The correlation coefficient between the level of logistics specialization and the degree of betweenness centrality is not significant, indicating that the logistics mode of node cities is single, and the informatization and standardization need to be improved.

\section{Introduction}

The logistics industry integrates activities such as production, warehousing, wholesale and retail, telecommunications and effectively combines physical logistics and information circulation to cover integrated activities in the intersection of three industries. Its development level plays a vital role in stimulating the regional economy's vitality [1, 2]. [3] have tested the positive influence of logistics infrastructure construction on the regional trade level. Building a smart logistics network, increasing the density of channels, and maximizing logistics' stock resources effectively achieve material space benefits and economies of scale $[4,5]$.

In recent years, scholars have researched the correlation generated in the operation of logistics activities, and the methods to describe the structure of spatial networks are also diversified [6, 7]. These studies generally use cross-sectional data and time-series data of the whole country, urban agglomeration, or region to verify the economic spillover effect of logistics network from one or two dimensions, emphasizing the importance of logistics network with perfect spatial correlation. For example[8] explored the importance of logistics transportation to the American economy through time-series data, used an input-output table as the data source, and used the social network analysis method as a tool to analyze the overall economic pattern of the United States, highlighting the massive influence of logistics transportation industry. Sharma took the social welfare supply chain provided by Indian NGOs after the disaster as an example to simulate spatial network relationships and use social network analysis to analyze the flexibility and capabilities of the supply chain[9]. Song's research object is the world's major airports, and the overall and individual indicators in the social network analysis are calculated to enhance the accessibility of the air transportation network of various countries[10]. Zhong observed the significant industrial agglomeration phenomenon of the logistics industry in the Yangtze River Economic Zone, using spatial Gini coefficient and autocorrelation analysis to describe the spatial structure and the evolution characteristics of logistics industry agglomeration and reveal the factors affecting the level of logistics industry agglomeration[11].

The above literature mainly aims at studying the structure of spatial network association relations, focusing on the description of network layout, while the research on individual node cities is still incomplete. Some literature regarding node cities as individuals with the same logistic attraction ability lacks consideration of the gravitational heterogeneity caused by urban development and resource allocation structure and ignores the correlation between urban attributes. Some other literature only put the perspective inside node cities, believing that complete urban economic development and logistics can generate logistics attraction and build logistics relationship networks. However, it lacks the pulling effect on other cities in the network except for this node.

In short, the study of logistics spatial correlation structure, or module between the city and the city shall be full attention to the existence of the interaction between modules and heterogeneity, and because of this force will change with time-series data, the relationship of coverage and the steady performance also reflected the different characteristics in different

Page 2/19 
periods. This paper applies the modified universal gravitation model to social networks analysis and describes the evolution of the logistics network's spatial association with cross-section data from 2010 to 2018. Then identify the status of 21 cities in the province in the spatial grid, and emphasize the network characteristics differences of each node city in the logistics spatial network. Finally, QAP analysis, which can overcome multicollinearity among variables, is used to carry out regression analysis on the influencing factors of regional logistics spatial correlation in Sichuan province. This paper proposes to optimize the regional logistics network in Sichuan province to improve the overall logistics efficiency and promote the regional coordinated development through the research results.

\section{Material And Methods}

\subsection{The gravity model of logistics spatial relation 2.1.1 Gravity coefficient measure}

The gravity model dates back to 1946, G.K.zipf and J.Q. Wart used the universal gravitation model in physics for the first time to analyze the interaction of urban space [12]. In the partially modified gravity model, gravity's coefficient is generally consistent with that of the traditional gravity model, which is one or some constant $[13,14]$. But actually, the logistics links between cities are directional. The gravitational coefficient's optimization should reflect the influence on inter-city logistics action intensity's direction and size. The greater the gravitational coefficient of one city in another city, the greater the attraction. The concrete form is as follows:

$$
K_{i j}=\frac{G_{i}}{G_{\mathrm{i}}+G_{\mathrm{j}}}
$$

1

Among them, $K_{i j}$ represents the gravitational coefficient of city $i$ when it exerts logistic gravity on city $j, G_{i} \square G_{j}$ are the freight volume of $i$ and $j$ urban highways. It fully shows that in the logistics activities between the two cities. The weight of the city $i$ to the logistics connection of city $j$ is also the contribution rate of city $i$ to $K_{i j}$.

\subsubsection{City quality measure}

This paper draws on the existing literature $[15,16]$. The measured index with a high frequency of use is concluded(Table1), It is integrated and selected to illustrate the size of city quality with the most accurate and easy to obtain indexes that will not produce redundant waste.

Table.1 Indicator and definitions of city quality measurement 


\begin{tabular}{|ll|}
\hline Index & Definition \\
\hline Freight Ton-kilometers of Highways(10000 ton-kilometers) & Road freight capacity \\
\hline Number of Employed Persons in Transport, Storage and Post(10000 persons) & Logistics of human resources scale \\
\hline Total Length of Highways(km) & Level of logistics infrastructure \\
\hline Total Investment in Fixed Assets(100 million yuan) & Capital attraction ability \\
\hline Public Budget Expenditure in Transport(10000 yuan) & Connectivity potential \\
\hline Gross Regional Product(100 million yuan) & Regional economic level \\
\hline Per Capita Gross Regional Product(10000 yuan) & Regional per capita economic level \\
\hline Tertiary Industry(100 million yuan) & Structure of economic development \\
\hline Total Imports and Exports(USD 10000) & External economic relations \\
\hline Total Retail Sales of Consumer Goods(10000 yuan) & Consumption ability \\
\hline Number of Mobile Telephones Subscribers(subscribers) & Degree of informatization \\
\hline
\end{tabular}

These 11 indicators cover the fundamental development of the city's logistics, the level of the regional economy, and the degree of informatization and reflect the overall status and development potential of the city's logistics development level.

Principal component analysis (PCA) reduces the variables in the overlapping part of the original indicator system. The principal components are selected according to the principle that the cumulative variance contribution rate is greater than $85 \%$, and the eigenvalue is greater than 1 . The variance maximization orthogonal rotation is performed on the factor loading matrix, and the city quality $M$ is calculated using the weighted variance contribution rate after rotation.

\subsubsection{City distance measure}

In the logistics spatial relation structure, the urban distance not only refers to the spatial distance between the two cities on the earth but also takes into full consideration the actual traffic factors, which can reflect the corresponding changes of geographical features, traffic network, and economic factors during the formation and development of the spatial structure. Under normal circumstances, the gravity formula considers highway mileage, waterway mileage, railway mileage, or aviation mileage. Since there are few ports in Sichuan Province, this article uses highway mileage and per capita GDP to illustrate the city's potential supply capacity for logistics activities. The specific form is as follows:

$$
D_{i j}=\frac{d_{i j}}{g_{\mathrm{i}}+g_{\mathrm{j}}}
$$

2

Among them, the $D_{i j}$ said $i$ cities and city $j$ distance between cities, $d_{i j}$ is the actual distance between $i$ and $j$ cities, $g_{\mathrm{i}}$ and $g_{\mathrm{j}}$ respectively represent the per capita GDP of city $i$ and $j$, and the sum of the per capita GDP of both sides is used to measure the scale and flow of logistics activities.

\subsubsection{Gravitational modeling}

Assuming that internal logistics activities in Sichuan province are a closed system free from external interference, the concrete model is constructed as follows:

$$
R_{i j}=K_{i j} \frac{M_{\mathrm{i}} M_{\mathrm{j}}}{D_{i j}{ }^{2}}
$$


Where, $K_{i j}$ is the gravitational coefficient of city $i$ to city $j, M_{\mathrm{i}} \square M_{\mathrm{j}}$ respectively cities iand $j$ city quality, $D_{i j}$ for a correction after city distance, $R_{i j}$ for $i l j$ logistics attraction between the two cities, reflects the city in a certain period $i$ contact $j$ city logistics, on the logistics' strength that the greater the gravity between the two cities, both more frequent and stable logistics business, logistics contact closely.

The average value of each row in the gravity matrix is taken as the threshold value. If a gravitation value in the row is greater than the threshold value, it is denoted as 1 , indicating an association relationship between the two cities in the logistics activities. Otherwise, it is 0 , meaning that there is no correlation. A binary logistic space correlation matrix is constructed.

\subsection{Social network analysis}

Social network analysis is a method to describe the overall network structure and the correlation between nodes by transforming the spatial system into quantitative relational data and establishing a visual relational model among network nodes. Social network analysis has been carried out in organizational membership [17, 18], resource circulation[19], disease transmission network[20], regional economy [21] and other fields have been further studied.

\subsubsection{Overall network indicator}

Network density is used to describe the connection between each node's members in the network, and its value indicates the closeness of the logistics relationship between cities. The specific manifestations are as follows:

$$
D=\frac{L}{N \square N-1 \square}
$$

4

Where $D$ is the network density, $L$ is the actual number of relationships in the network, and $N$ is the number of actors in the network.

Network connectedness indicates whether a connection can be established between any nodes in the network. Simultaneously, the degree of overall network relevance is obtained, which reflects the independence and fragility of the interconnection structure network of logistics between cities. The concrete form is as follows:

$$
C=1-\left[\frac{V}{N \square N-1 \square / 2}\right]
$$

\section{5}

Where $C$ is network correlation, $V$ is the logarithm of unreachable points in the network, and $N$ is the number of actors in the network.

\subsubsection{Individual network indicator}

Degree centrality reflects the number of nodes directly connected to a node in the network, Indegree means the number of nodes benefited association, and Outdegree implies the number of overflow associations. If a city has the highest degree of point degree, it has the most connections with other cities and is considered in the network center. It may have the most significant right to manipulate the overall logistics network and control other cities' development within a certain period. The specific form is as follows: 


$$
D e=\frac{n}{N-1}
$$

6

Where $D e$ is the degree centrality, $n$ is the number of other cities directly related to a city, and $N$ is the number of cities that are most likely to be connected to it.

Betweenness centrality is used to describe the degree of control of a node over other nodes. Cities at the core of the network can control more node cities and have great power, while cities at the edge of the network cannot. The specific form is as follows:

$$
C_{A B i}=\sum_{j}^{n} \sum_{k}^{n}\left[\frac{g_{j k} \square i \square}{g_{j k}}\right]
$$

\section{7}

Where, $C_{A B i}$ is the betweenness centrality of point $i$, and $i$ is the third point between point $j$ and $k$. The number of shortcuts between $j$ and $k$ is expressed by $g_{j k}$. The number of shortcuts through the point $i$ is denoted by $g_{j k} \square i \square$, where $j \neq k \neq i$, and $j<k$.

Closeness centrality measures the sum of the shortcut distances between a node and all other network nodes. Cities with high closeness centrality indicate more direct connections with other cities in the logistics network. The concrete form is as follows:

$$
C_{A P i}^{-1}=\sum_{j=1}^{n} d_{i j}
$$

8

Where, $C_{A P i}^{-1}$ is the closeness centrality, and $d_{i j}$ is the shortcut distance between point $i$ and $j \square$

\subsubsection{Block model}

The block model is a method of studying the location of the network. It uses specific standards to divide the nodes into several blocks. The nodes in these blocks rely on some common properties to produce more close connections than any node outside the block. The nodes in each block have structural equivalence, and the internal structure division of the logistics network can be judged from the position. These positions are divided into four role plates: the main beneficiary plate, the net beneficiary plate, the two-way overflow plate, and the broker plate.

The logistics connections generated by the main beneficiary plate within the plate account for a larger proportion of the overall links, while the links outside the plate are relatively small. The net beneficiary plate means that the plate has more connections with external nodes and neglects logistics activities with other plate nodes. The two-way overflow plate has issued a large number of logistics relationships both within and outside the plate. The broker plate accepts both internal and external connections, but there is less communication between nodes within the block.

\subsection{QAP analysis}

QAP (Quadratic Assignment Procedure) is a non-traditional correlation measurement method. By resampling, the rows and columns of the matrix are replaced simultaneously, and the correlation between the two relational matrices corresponding to each grid value is analyzed. Give the correlation coefficients between the relationship matrices and perform non- 
parametric tests. The QAP null hypothesis's essence is to reorder another matrix structure based on fixed matrix network relations. This test method can negate the virtual correlation between relational matrices [22, 23].

The interweaving relationship between the nodes forms the logistics space network. The change of individual network indicators will also have a counter-effect to the space network, that is, the performance of promoting or hindering the professional level of urban logistics activities. In the process of measuring point degree centrality, betweenness centrality, closeness centrality, 11 raw data covering the logistics development level, industrial economic structure, and informationization level are used. To eliminate the influence of the correlation between the existing explanatory variables and the explained variables, the government's funding for scientific and technological research[24, 25], the number of existing trucks [26,27], and the total capital of commercial business building development investment [28] are added as explanatory variables.

The level of specialization of logistics is calculated as follows:

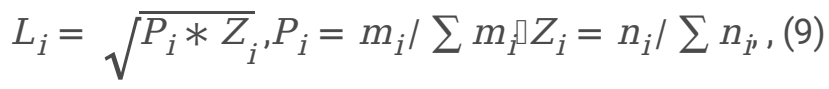

Where $L_{i}$ is the comprehensive index of urban logistics specialization, $P_{i}$ is the acceptance index of logistics activities, $Z_{i}$ is the scale index of the logistics industry, and $m_{i}$ and $n_{i}$ respectively represent the number of people employed in transportation, warehousing, and postal services and the turnover volume of goods transportation in each city.

This paper makes the following theoretical hypothesis: The professional level of urban logistics in Sichuan province logistics network is mainly affected by six factors, which are respectively caused by point degree center $D$, proximity degree $C$, intermediary degree $B$, science and technology research allocation $S_{a^{\prime}}$, number of trucks $I$, and commercial business development investment $C_{i}$. The following model can be established:

$$
L_{i}=f\left(D, C, B, S_{a}, I, C_{i}\right)
$$

10

\subsection{Data sources}

In this paper, 21 cities in Sichuan province are taken as research objects (shown in Figure 1). Sichuan is divided into five economic zones, namely Chengdu Economic Zone (blue), Northeast Sichuan Economic Zone (gray), South Sichuan Economic Zone (yellow), Panxi Economic Zone (orange), and Northwest Sichuan Economic Zone (red). To fully reflect the development trend and characteristics of regional logistics links, data from 2010 to 2018 are used as samples to ensure a long period and data availability and accuracy. The data used in this paper are mainly from the 'Sichuan Statistical Yearbook' from 2010 to 2019, and some of the missing data are used to complete the data in 'The Statistical Bulletin of National Economic and Social Development' of Sichuan cities from 2010 to 2019. The distance between cities is the shortest road distance between two cities on the Baidu map. The data of science and technology research appropriations, the number of trucks available in each city, and the investment amount in the development of commercial business houses were obtained from 'Sichuan Science' and 'Technology Yearbook' 'Sichuan Transportation Yearbook' and 'Sichuan Real Estate Yearbook' in 2017, respectively. SPSS 22.0 and UCINET 6.0 were used to process the original data.

\section{Analysis Of Empirical Results}

\subsection{Measurement results}

In this paper, 11 indicators are selected to measure the comprehensive logistics level of each city. Take the city quality of Sichuan Province in 2016 as an example; SPSS software is used for principal component analysis(Table2)ם 
Table.2 Eigenvalue and variance contribution rate

\begin{tabular}{|c|c|c|c|c|c|c|c|c|c|}
\hline \multirow[t]{2}{*}{ Component } & \multicolumn{3}{|c|}{ Initial Eigenvalues } & \multicolumn{3}{|c|}{$\begin{array}{l}\text { Extraction Sums of Squared } \\
\text { Loadings }\end{array}$} & \multicolumn{3}{|c|}{$\begin{array}{l}\text { Rotation Sums of Squared } \\
\text { Loadings }\end{array}$} \\
\hline & Total & $\begin{array}{l}\% \text { of } \\
\text { Variance }\end{array}$ & $\begin{array}{l}\text { Cumulative } \\
\%\end{array}$ & Total & $\begin{array}{l}\% \text { of } \\
\text { Variance }\end{array}$ & $\begin{array}{l}\text { Cumulative } \\
\%\end{array}$ & Total & $\begin{array}{l}\% \text { of } \\
\text { Variance }\end{array}$ & $\begin{array}{l}\text { Cumulative } \\
\%\end{array}$ \\
\hline 1 & 8.381 & 76.187 & 76.187 & 8.381 & 76.187 & 76.187 & 7.956 & 72.323 & 72.323 \\
\hline 2 & 1.700 & 15.454 & 91.642 & 1.700 & 15.454 & 91.642 & 2.125 & 19.318 & 91.642 \\
\hline 3 & 0.423 & 3.841 & 95.483 & & & & & & \\
\hline 4 & 0.314 & 2.855 & 98.338 & & & & & & \\
\hline 5 & 0.156 & 1.422 & 99.760 & & & & & & \\
\hline 6 & 0.011 & 0.099 & 99.859 & & & & & & \\
\hline 7 & 0.007 & 0.062 & 99.921 & & & & & & \\
\hline 8 & 0.006 & 0.051 & 99.973 & & & & & & \\
\hline 9 & 0.002 & 0.014 & 99.987 & & & & & & \\
\hline 10 & 0.001 & 0.010 & 99.997 & & & & & & \\
\hline 11 & 0.000 & 0.003 & 100.000 & & & & & & \\
\hline
\end{tabular}

It can be found from Table 2 that the cumulative variance contribution rate of the first two principal components is $91.642 \%$, and their eigenvalues are all greater than 1, indicating that they cover most of the critical information of 11 data.

Orthogonal rotation of the variance maximization of the factor load matrix is carried out (Table3). After rotation, the two principal components' factor coefficients begin to show polarization, which can better explain the index data's attributes. The first principal component coefficient is close to 1 with 9 indexes, and the coefficient of the second principal component is larger with 2 indexes. The index with a large first principal component coefficient mostly describes the development status of urban logistics, and the description of logistics activity potential is more material promotion. However, the index with a larger principal component coefficient is positioned as the driving force of urban development and the prospect, emphasizing the leverage effect of investment concentration in the whole society.

Table.3 The rotated factor load matrix 


\begin{tabular}{|lll|}
\hline & Component 1 & Component 2 \\
\hline Freight Ton-kilometers of Highways & 0.816 & 0.240 \\
\hline Number of Employed Persons in Transport, Storage and Post & 0.971 & 0.188 \\
\hline Total Length of Highways & 0.093 & 0.957 \\
\hline Total Investment in Fixed Assets & 0.963 & 0.230 \\
\hline Public Budget Expenditure in Transport & 0.356 & 0.827 \\
\hline Gross Regional Product & 0.980 & 0.172 \\
\hline Per Capita Gross Regional Product & 0.746 & -0.425 \\
\hline Tertiary Industry & 0.974 & 0.206 \\
\hline Total Imports and Exports & 0.968 & 0.193 \\
\hline Total Retail Sales of Consumer Goods & 0.975 & 0.195 \\
\hline Number of Mobile Telephones Subscribers & 0.963 & 0.226 \\
\hline
\end{tabular}

It can be seen from Table 4 that Chengdu's first principal component score is significantly higher than other cities, and the city quality measurement result is also the largest. This shows that Chengdu attaches more importance to logistics activities and has a good foundation for the logistics development. The second principal component score of Ganzi is the highest, indicating that Sichuan province has begun to gradually pay attention to the transportation inconvenience of the western Sichuan region, realized the importance of a good logistics network, and intended to make it a significant thrust for the optimization of the structure and function of logistics network in Sichuan Province]

In Table2, the variance contribution rate is taken as the weight, and the calculation formula of city quality is:

$$
M=\frac{V_{1}}{V_{1}+V_{2}} F A C 1+\frac{V_{2}}{V_{1}+V_{2}} F A C 2
$$

11

Since the negative number of urban mass is not convenient to continue to calculate the gravitational strength of each city's logistics, the results are parallel and amplified, and the newly adjusted urban massM' $=(M+6) \times 10$

Table.4 Quality measurement results of cities in Sichuan Province in 2016 


\begin{tabular}{|lcccl|}
\hline Cities & FAC1 & FAC2 & $\boldsymbol{M}$ & $\boldsymbol{M}^{\prime}$ \\
\hline Chengdu & 4.196 & 0.938 & 3.216 & 92.160 \\
\hline Zigong & 0.019 & -1.095 & -0.198 & 58.022 \\
\hline Panzhihua & 0.273 & -1.921 & -0.174 & 58.265 \\
\hline Luzhou & 0.009 & -0.072 & -0.007 & 59.925 \\
\hline Deyang & 0.152 & -1.071 & -0.097 & 59.029 \\
\hline Mianyang & -0.031 & 0.302 & 0.036 & 60.362 \\
\hline Guangyuan & -0.492 & 0.554 & -0.248 & 57.516 \\
\hline Suining & -0.253 & -0.642 & -0.307 & 56.929 \\
\hline Neijiang & -0.206 & -0.661 & -0.277 & 57.231 \\
\hline Leshan & 0.042 & -0.395 & -0.046 & 59.542 \\
\hline Nanchong & -0.253 & 0.932 & -0.003 & 59.973 \\
\hline Meishan & -0.124 & -0.818 & -0.248 & 57.521 \\
\hline Yibin & -0.153 & 0.238 & -0.065 & 59.355 \\
\hline Guangan & -0.234 & -0.616 & -0.289 & 57.113 \\
\hline Dazhou & -0.119 & 0.538 & 0.017 & 60.175 \\
\hline Yaan & -0.283 & -0.555 & -0.312 & 56.880 \\
\hline Bazhong & -0.583 & 0.477 & -0.330 & 56.705 \\
\hline Ziyang & -0.188 & -0.302 & -0.194 & 58.060 \\
\hline Aba & -0.504 & 0.180 & -0.330 & 56.704 \\
\hline Ganzi & -0.992 & 2.624 & -0.211 & 57.892 \\
\hline Liangshan & -0.276 & 1.367 & 0.064 & 60.641 \\
\hline
\end{tabular}

\subsection{Analysis of the Spatial Correlation Structure}

\subsubsection{The whole logistics}

The modified gravity model was used to calculate the numerical value of the interaction in the logistics network formed between cities, and then binarization was carried out to construct the association structure matrix. Ucinet software is used to draw the network association structure diagram shown in Figure 2. In this paper, the year 2010 (correlation number is 105), 2013 (correlation number is 111), 2016 (correlation number is 116), and 2018 (correlation number is 114) are selected as representative data to be drawn. The four network correlation structure charts reflect the connectivity of logistics relations between cities. It can be seen from Figure 2 that from 2010 to 2018 , the number of connections continued to increase, and the logistics activities between cities have become closer. Sichuan Province has realized the sharing of some resources and infrastructure and has increased its resistance to economic fluctuations, which has promoted the coordinated development of logistics networks to a certain extent.

In 2010, the number of spatial correlations was 105 and kept rising until 2013, when the number reached 111. In the following two years, the number was flat. However, in 2016, there was a relatively noticeable change, which was also the year with the most spatial correlation among the nine years of data studied in this paper, rising to 116 . Since then, it has 
shown a smaller decline. After 115 in 2017, the number of correlations dropped to 114 in 2018 . The above data shows that the spatial correlation structure of logistics in Sichuan Province is complex, and cities' connections are close. There is still much room for improvement in the coordination and cooperation capabilities between logistics nodes and the logistics network's stable operation.

As shown in Figure 3, Sichuan's logistics network's overall density rose from 0.250 in 2010 to 0.271 in 2018 . In 2011 and 2016 , the overall density showed a particular leapfrog development, growing by $3.8 \%$ and $5.5 \%$, respectively, compared with the previous year. The improvement of correlation number and network density directly depicts the gradual improvement process of logistics network in Sichuan province, which is in an excellent running state and reflects specific spillover effect, which strongly promotes the mutual learning and integration of facilities, technologies, and policies among cities in the province. According to the calculation, the network correlation between 2010 and 2018 is all 1, indicating that the logistics network's daily operation in Sichuan province is smooth, with a low possibility of rupture and overall solid robustness.

\subsubsection{Individual Logistics Network}

To further study each region's position in Sichuan logistics' spatial association structure, this paper selects 2016 as the representative, and analyzes the degree centrality, betweenness centrality, and closeness centrality.

It can be seen from Table 5, the average degree of 21 cities in Sichuan province is 41.905, and 10 cities above this value. They are located in the central region of Sichuan province, which has a sure economic foundation and a bright prospect of logistics development. For the Outdegree, Suining, Bazhong, Ganzi, and Aba all reach 8, which is in a high-value position. The city with the smallest Outdegree is Mianyang, which is only 2. This difference is that Ganzi and Aba account for approximately $48.80 \%$ of the total area of Sichuan Province and are rich in mineral resources, animal and plant resources. It is necessary to export resources further to transform them into financial ability and economic advantage.

From the analysis of InDegree, the cities with an InDegree greater than 10 are Chengdu, Ziyang, Deyang, and Zigong. It can be seen from this that Chengdu and surrounding cities have high logistics attracting capacity, which is inseparable from the acceleration of infrastructure construction, investment promotion, and talent introduction in Sichuan Province in recent years. It has given the city of Chengdu too high economic vitality and has even begun to promote Sichuan province's development positively. With an InDegree of 0 , Aba is in the least active position in the overall logistics network.

Cities with a high Outdegree are mainly concentrated in the eastern part of Sichuan province, directly bordering other fastgrowing regions around or some cities scattered in all directions with Chengdu as the center. The Outdegree in Sichuan province is controlled at a relatively stable level, indicating that the overall logistics activities have strong synergies, which transcend geographical conditions and form a wide range of netlike logistics connections. Meanwhile, some developed cities promote the stability of related structures with their development gravity. Cities with high InDegree form an approximate circle, indicating that logistics activities are highly concentrated. Regional isolation has not yet been broken, and it is less attractive to peripheral cities' logistics.

Table.5 Degree centrality of logistics spatial network in Sichuan province in 2016 


\begin{tabular}{|lllll|}
\hline Cities & OutDegree & InDegree & Centrality & Rank \\
\hline Chengdu & 5 & 17 & 85.000 & 1 \\
\hline Zigong & 4 & 10 & 50.000 & 5 \\
\hline Panzhihua & 5 & 1 & 25.000 & 18 \\
\hline Luzhou & 5 & 2 & 25.000 & 18 \\
\hline Deyang & 3 & 11 & 55.000 & 3 \\
\hline Mianyang & 2 & 6 & 30.000 & 15 \\
\hline Guangyuan & 7 & 1 & 35.000 & 14 \\
\hline Suining & 8 & 6 & 55.000 & 3 \\
\hline Neijiang & 3 & 9 & 45.000 & 8 \\
\hline Leshan & 7 & 6 & 40.000 & 11 \\
\hline Nanchong & 3 & 5 & 30.000 & 15 \\
\hline Meishan & 7 & 7 & 50.000 & 5 \\
\hline Yibin & 5 & 4 & 25.000 & 18 \\
\hline Guangan & 6 & 5 & 45.000 & 8 \\
\hline Dazhou & 6 & 1 & 30.000 & 15 \\
\hline Yaan & 6 & 6 & 45.000 & 8 \\
\hline Bazhong & 8 & 2 & 40.000 & 11 \\
\hline Ziyang & 7 & 13 & 65.000 & 2 \\
\hline Aba & 8 & 0 & 40.000 & 11 \\
\hline Ganzi & 8 & 3 & 50.000 & 5 \\
\hline Liangshan & 3 & 1 & 15.000 & 21 \\
\hline Mean & 5.524 & 5.524 & 41.905 & \\
\hline
\end{tabular}

It can be seen from Table 6, the top three cities with betweenness centrality are Ziyang, Chengdu, and Suining. Their betweenness centrality accounts for a total of 165.65 , accounting for $56.73 \%$ of the total cities. The top-ranking cities are located in the central part of Sichuan Province, which are the main economic activity areas in the province and have sufficient logistics development conditions. The betweenness centrality of Nanchong, Guangyuan, Mianyang, Aba, Dazhou, and Liangshan are all 0 , and these cities are located on the edge of Sichuan Province. It is challenging to produce the scale effect of industrial agglomeration, and the ability to promote the development of the overall logistics network is weak.

Table.6 Closeness Centrality of logistics spatial network in Sichuan province in 2016 


\begin{tabular}{|c|c|c|c|c|}
\hline Cities & InCloseness & QutCloseness & Centrality & Rank \\
\hline Chengdu & 86.957 & 13.072 & 86.957 & 1 \\
\hline Zigong & 62.500 & 12.821 & 64.516 & 7 \\
\hline Panzhihua & 5.000 & 16.949 & 55.556 & 19 \\
\hline Luzhou & 40.000 & 12.987 & 57.143 & 15 \\
\hline Deyang & 68.966 & 12.658 & 68.966 & 3 \\
\hline Mianyang & 54.054 & 12.121 & 57.143 & 15 \\
\hline Guangyuan & 5.249 & 21.053 & 58.824 & 14 \\
\hline Suining & 54.054 & 13.423 & 68.966 & 3 \\
\hline Neijiang & 60.606 & 12.739 & 62.500 & 10 \\
\hline Leshan & 58.824 & 13.423 & 62.500 & 10 \\
\hline Nanchong & 38.462 & 12.821 & 57.143 & 15 \\
\hline Meishan & 60.606 & 13.423 & 66.667 & 5 \\
\hline Yibin & 45.455 & 13.072 & 47.619 & 21 \\
\hline Guangan & 38.462 & 13.245 & 64.516 & 7 \\
\hline Dazhou & 5.249 & 20.833 & 57.143 & 15 \\
\hline Yaan & 44.444 & 13.245 & 64.516 & 7 \\
\hline Bazhong & 5.263 & 21.277 & 60.606 & 13 \\
\hline Ziyang & 74.074 & 13.514 & 74.074 & 2 \\
\hline Aba & 4.762 & 15.504 & 62.500 & 10 \\
\hline Ganzi & 32.258 & 13.514 & 66.667 & 5 \\
\hline Liangshan & 5.000 & 16.260 & 50.000 & 20 \\
\hline Mean & 40.488 & 14.664 & 62.596 & \\
\hline
\end{tabular}

\subsubsection{Network Block}

In the block model analysis, the adjusted maximum segmentation depth is 2, and the convergence standard is 0.2 . Therefore, according to the spatial clustering characteristics of the logistics network in Sichuan Province, 21 cities can be divided into four plates with different commonalities, as shown in Figure 4.

The correlation number of the overall logistics network in Sichuan province in 2016 is 116 . Table 7 shows that the number of relationships within the four blocks is 65 , and the number of connections between the four blocks is 51 , indicating that the overall logistics development of Sichuan Province is based on urban agglomerations. The urban part of the first plate is located in the Chengdu Plain Economic Zone, and it also includes the entire area of the Northwest Sichuan Ecological Economic Zone and the Panxi Economic Zone and covers the western part of Sichuan Province. The second section covers some cities in the Southern Sichuan Economic Zone and the Chengdu Plain Economic Zone, and is located in the southeast of Sichuan Province. The third plate is located in the central part of Sichuan, close to Chengdu. The fourth sector belongs to cities in the Northeast Sichuan Economic Zone and is the center of regional economic integration between Sichuan, Chongqing, Shaanxi, and Gansu. The spatial relationship within the urban agglomeration is stable, and there are spillover effects that cannot be ignored in the logistics activities between the plates. 


\begin{tabular}{|c|c|c|c|c|c|c|}
\hline \multirow[t]{2}{*}{ Plate } & \multicolumn{2}{|c|}{$\begin{array}{l}\text { Number of } \\
\text { acceptance relations }\end{array}$} & \multicolumn{2}{|c|}{$\begin{array}{l}\text { Number of emitted } \\
\text { relations }\end{array}$} & \multirow[t]{2}{*}{$\begin{array}{l}\text { The ratio of expected internal } \\
\text { relationships(\%) }\end{array}$} & \multirow[t]{2}{*}{$\begin{array}{l}\text { Actual internal } \\
\text { relationship ratio(\% }\end{array}$} \\
\hline & $\begin{array}{l}\text { In the } \\
\text { plate }\end{array}$ & $\begin{array}{l}\text { Outside } \\
\text { the } \\
\text { plate }\end{array}$ & $\begin{array}{l}\text { In the } \\
\text { plate }\end{array}$ & $\begin{array}{l}\text { Outside the } \\
\text { plate }\end{array}$ & & \\
\hline $1 \mathrm{st}$ & 21 & 14 & 21 & 21 & 30.00 & 50.00 \\
\hline 2ed & 23 & 21 & 23 & 8 & 25.00 & 74.19 \\
\hline $3 r d$ & 2 & 15 & 2 & 3 & 5.00 & 40.00 \\
\hline 4th & 19 & 1 & 19 & 19 & 25.00 & 50.00 \\
\hline
\end{tabular}

The total number of relations emitted by the first plate is 42, among which 21 are generated within the plate. The expected proportion of internal links is $30 \%$, while the actual ratio of internal relations is $50 \%$, called a two-way overflow plate. The number of relationships generated inside the second plate is 23 , and there are 8 relationships outside the plate. The expected ratio of internal relationships is $25 \%$, and the actual ratio of internal relationships is $74.19 \%$, serving as the net benefit plate. The third plate gives out 5 correlation relations and produces 2 internally. The expected ratio of internal relations is $5 \%$, but the actual ratio of internal relations is $40 \%$, the main beneficiary plate. The number of relations emitted from the fourth plate's interior is 19 , and the same number of relations are emitted from the exterior plate. The expected proportion of internal relations is $25 \%$, while the actual ratio of internal relations is $50 \%$, considered the economic man plate.

\subsection{Analysis of the Influencing Factors}

According to the calculation results of 5000 random substitutions, the results are shown in table 8 . The development investment of the urban commercial business has a substantial impact on the professional development of the city's logistics. The reason for this result may be that the existing logistics activities are mostly based on commodity circulation. However, the correlation coefficient between the logistics specialization matrix $L_{i}$ and the betweenness centrality $B$ is not significant, indicating that the logistics mode of the node city as a logistics intermediary is single. The degree centrality $D$, the closeness centrality $C$, the science and technology research grants $S_{a}$ and the number of trucks $I$ are calculated to reflect their positive influence on the degree of professional development of urban logistics.

Table.8 The results of QAP correlation analysis

\begin{tabular}{|lllllllll|}
\hline Variable & $\begin{array}{l}\text { Actual correlation } \\
\text { coefficient }\end{array}$ & $\begin{array}{l}\text { Significance } \\
\text { level }\end{array}$ & $\begin{array}{l}\text { Mean correlation } \\
\text { coefficient }\end{array}$ & $\begin{array}{l}\text { Standard } \\
\text { deviation }\end{array}$ & Min & Max & P $\geq 0$ & $P \leq 0$ \\
\hline$D$ & 0.638 & 0.026 & 0.001 & 0.174 & -0.148 & 0.697 & 0.026 & 0.974 \\
\hline$C$ & 0.676 & 0.044 & 0.002 & 0.190 & -0.150 & 0.726 & 0.044 & 0.956 \\
\hline$B$ & 0.333 & 0.102 & 0.004 & 0.191 & -0.125 & 0.728 & 0.102 & 0.898 \\
\hline$S_{a}$ & 0.697 & 0.020 & 0.003 & 0.209 & -0.119 & 0.759 & 0.020 & 0.980 \\
\hline$I$ & 0.953 & 0.025 & -0.001 & 0.215 & -0.100 & 0.967 & 0.025 & 0.975 \\
\hline$C_{i}$ & 0.985 & 0.005 & 0.004 & 0.229 & -0.082 & 0.988 & 0.005 & 0.995 \\
\hline
\end{tabular}

\section{Conclusions And Policy Implications}




\subsection{Conclusions}

Taking the regional logistics spatial association structure of Sichuan Province from 2010 to 2018 as the research object, this paper uses a gravity model to measure logistics activities' interrelationship among cities. Furthermore, it is using social network analysis to explore the overall and individual network characteristics. Simultaneously, the QAP method is used to verify the factors that restrict the specialization of logistics activities in each node city. The main research conclusions are as follows:

From the analysis of the overall logistics network space's correlation structure, The logistics relationship between cities has become closer year by year, and the construction of a Unicom logistics network covering the whole province has been gradually realized.

According to the correlation structure of individual logistics network space, the average degree centrality of 21 cities in Sichuan province in 2016 was 41.905, and 10 cities exceeded this value. These cities have three characteristics: first, they are located in the central part of Sichuan Province, bordering vital other towns. Second, it is rich in material resources. Third, it is located in the Chengdu Plain economic zone, with a particular financial foundation.

As for the block model results, the four blocks are consistent with the five major economic regions. However, the economic zone's transportation facilities and monetary policies are not perfect, so the urban barriers have not been broken, and the overall network connectivity still has room for improvement. There is an urgent need to strengthen cooperation between blocks to improve the overall logistics network efficiency of Sichuan Province.

Through QAP correlation analysis, it is found that commercial business development investment has a particularly significant impact on the logistics specialization composite index, and it is relatively sensitive to the number of trucks. However, the informatization, standardization, and specialization still need to be improved.

\subsection{Policy implications}

Based on the above research results, this article proposes the following policy recommendations to improve the overall logistics network efficiency of Sichuan Province and the whole country.

Collaborative development of regional logistics. Make use of each city's economic development level and industrial advantages for functional positioning, forming a situation of complementary functions and cooperation. Following the requirements of the national industrial policy, rationally distribute productivity. Formulate incentives and preferential policies to guide foreign investment in resource development, infrastructure construction, and large-scale industries in Western Sichuan to realize the East and West's joint development.

Vigorously develop intelligent logistics. Promote the application of advanced technologies such as 5G, the Internet of Things, big data, and artificial intelligence in smart logistics. Accelerate the integration of digital infrastructure and thus drive innovation. The short-term "island effect" of logistics is developed into the long-term "crowding-out effect, fusion effect, and siphon effect" of the actual network effect based on cloud infrastructure.

Promote green logistics innovation. The government should restrict logistics enterprises' management with relevant policies and laws, so that green logistics can better develop and innovate. Green logistics technology research and development institutions can cooperate with enterprises to promote the innovative development of new technologies in the logistics industry and realize the effective connection of green logistics technology from research and development to practice.

\section{Declarations}

Funding: This work was supported by the National Social Science Fund [grant numbers 20BGL268]. 


\section{References}

1. Kisperskamoron, D. (1994). LOGISTICS CHANGE DURING THE TRANSITION PERIOD IN THE POLISH ECONOMY. International Journal of Production Economics, 35(1-3), 23-28

2. Lean, H. H., Huang, W., \& Hong, J. (2014). Logistics and economic development: Experience from China. Transport Policy, 32, 96-104

3. Bensassi, S., et al. (2015). Relationship between logistics infrastructure and trade: Evidence from Spanish regional exports. Transportation research part A: policy and practice, 72, 47-61

4. Liao, T. Y. (2018). Reverse logistics network design for product recovery and remanufacturing. Applied Mathematical Modelling, 60, 145-163

5. Xu, X. F., et al. (2017). Design optimization of resource combination for collaborative logistics network under uncertainty. Applied Soft Computing, 56, 684-691

6. Zhang, S., \& Cui, R. (2020). Logistics Efficiency Network Spatial Structure Based on Coastal City Shandong. Journal of Coastal Research, 104(SI), 322-327

7. Yang, C., Lan, S., \& Tseng, M. L. (2019). Coordinated development path of metropolitan logistics and economy in Belt and Road using DEMATEL-Bayesian analysis. International Journal of Logistics Research and Applications, 22(1), 124

8. lyengar, D., Rao, S., \& Goldsby, T. J. (2012). The power and centrality of the transportation and warehousing sector within the US economy: A longitudinal exploration using social network analysis. Transportation journal, 51(4), 373398

9. Sharma, M. G., \& Srivastava, S. K. (2016). Leveraging the social welfare chain to provide resilience during disaster. International Journal of Logistics Research and Applications, 19(6), 509-519

10. Song, M. G., \& Yeo, G. T. (2017). Analysis of the air transport network characteristics of major airports. The Asian Journal of Shipping and Logistics, 33(3), 117-125

11. Zhong, C. B., et al. (2017). Research on Logistics Industry Agglomeration and Its Influencing Factors in the Yangtze River Economic Belt--An Empirical Analysis Based on Spatial Durbin Model. East China Economic Management

12. Zipf, G. K. (1946). The P 1 P 2/D hypothesis: on the intercity movement of persons. American sociological review, 11(6), 677-686

13. Zainal Abidin, I. S., \& Haseeb, M. (2018). Malaysia-Gcc bilateral trade, macroeconomic indicators and islamic finance linkages: A gravity model approach. Academy of Accounting and Financial Studies Journal, 22(SI), 1-7

14. Çelebi, D. (2019). The role of logistics performance in promoting trade. Maritime Economics \& Logistics, 21(3), 307323

15. Zheng, W., Xu, X., \& Wang, H. (2020). Regional logistics efficiency and performance in China along the Belt and Road Initiative: The analysis of integrated DEA and hierarchical regression with carbon constraint. Journal of Cleaner Production, 276, 123649

16. Sun, Q. (2017). Empirical research on coordination evaluation and sustainable development mechanism of regional logistics and new-type urbanization: a panel data analysis from 2000 to 2015 for Liaoning Province in China.

Environmental Science and Pollution Research, 24(16), 14163-14175

17. Kim, J., \& Hastak, M. (2018). Social network analysis: Characteristics of online social networks after a disaster. International Journal of Information Management, 38(1), 86-96

18. Can, U., \& Alatas, B. (2019). A new direction in social network analysis: Online social network analysis problems and applications (535 vol., p. 122372). Physica A: Statistical Mechanics and its Applications 
19. Groce, J. E., et al. (2019). Using social-network research to improve outcomes in natural resource management. Conservation Biology, 33(1), 53-65

20. Stroeymeyt, N., et al. (2018). Social network plasticity decreases disease transmission in a eusocial insect. Science, 362(6417), 941-945

21. Zheng, X., et al. (2016). Review of the application of social network analysis (SNA) in construction project management research. International journal of project management, 34(7), 1214-1225

22. Burkard, R. E., et al. (1998). The quadratic assignment problem, in Handbook of combinatorial optimization (pp. 17131809). Springer

23. Simpson, W. (2001). QAP: The quadratic assignment procedure. in North American STATA users' group meeting.

24. Gunasekaran, A., Subramanian, N., \& Papadopoulos, T. (2017). Information technology for competitive advantage within logistics and supply chains: A review. Transportation Research Part E: Logistics and Transportation Review, 99, 14-33

25. Choi, T. M., et al. (2019). The mean-variance approach for global supply chain risk analysis with air logistics in the blockchain technology era. Transportation Research Part E: Logistics and Transportation Review, 127, 178-191

26. Taniguchi, E., \& Thompson, R. G. (2002). Modeling city logistics. Transportation research record, 1790(1), 45-51

27. Hu, L., et al. (2018). Joint design of fleet size, hub locations, and hub capacities for third-party logistics networks with road congestion constraints. Transportation Research Part E: Logistics and Transportation Review, 118, 568-588

28. Guerlain, C., Renault, S., \& Ferrero, F. (2019). Understanding Construction Logistics in Urban Areas and Lowering Its Environmental Impact: A Focus on Construction Consolidation Centres. Sustainability, 11(21), 6118

\section{Figures}

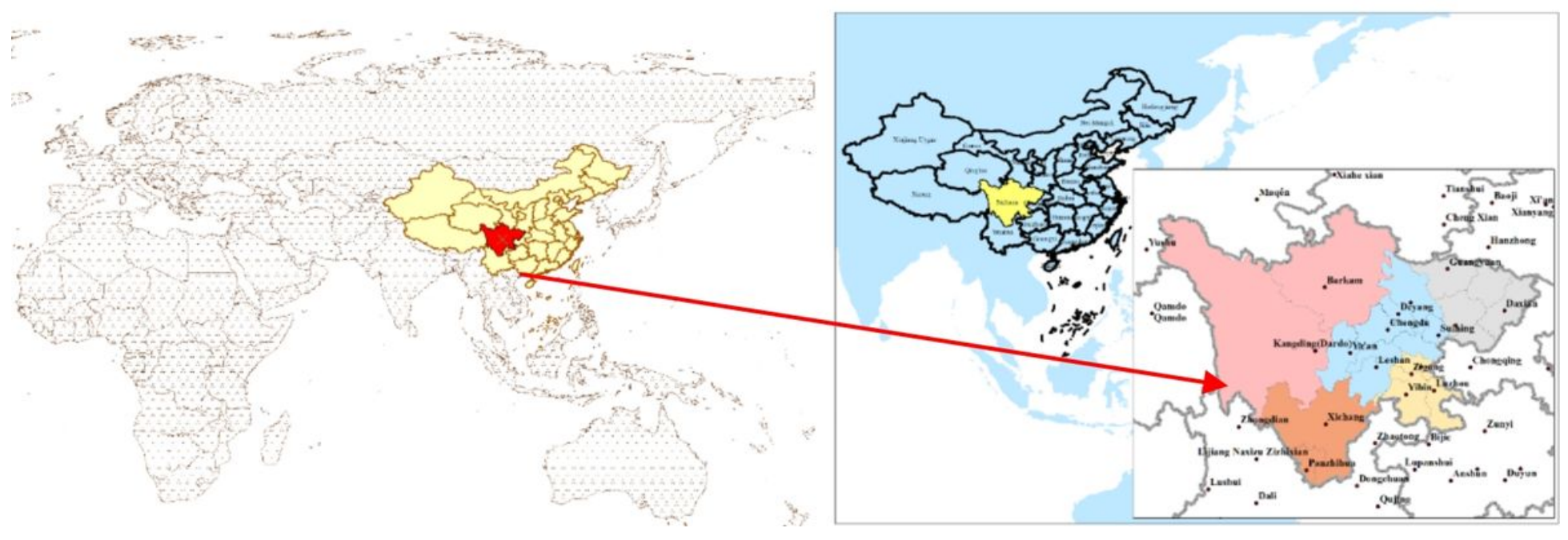

\section{Figure 1}

Map of Sichuan Province and five economic zones 

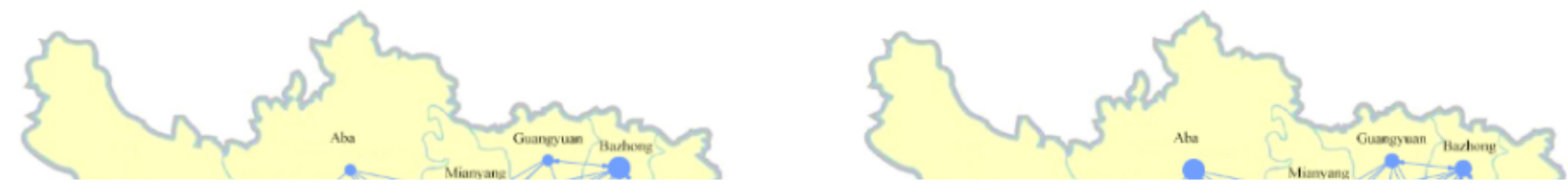

Figure 2

Logistics space association structure of Sichuan Province

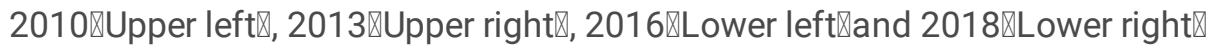




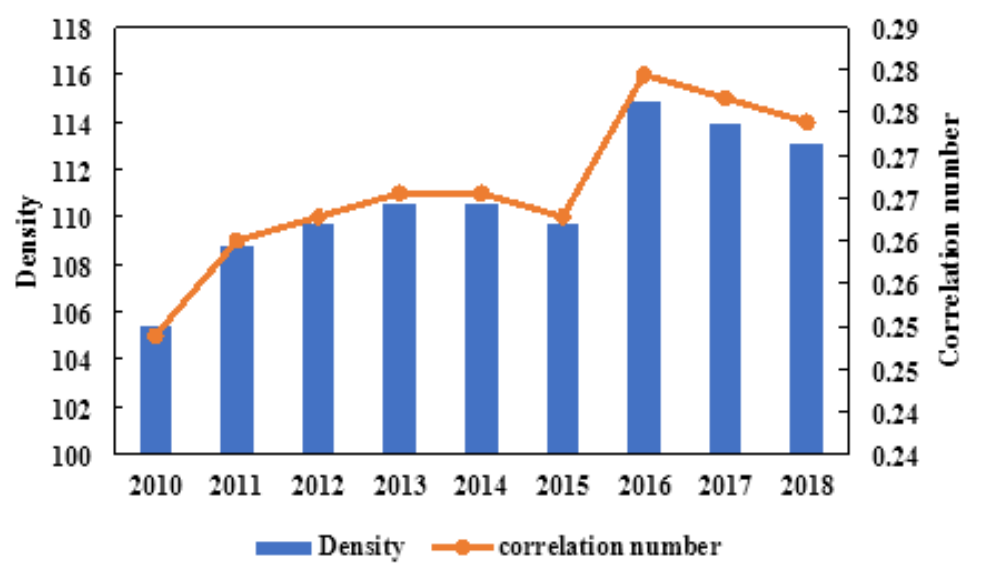

Figure 3

Correlation number and network density of Logistics network in Sichuan province from 2010 to 2018

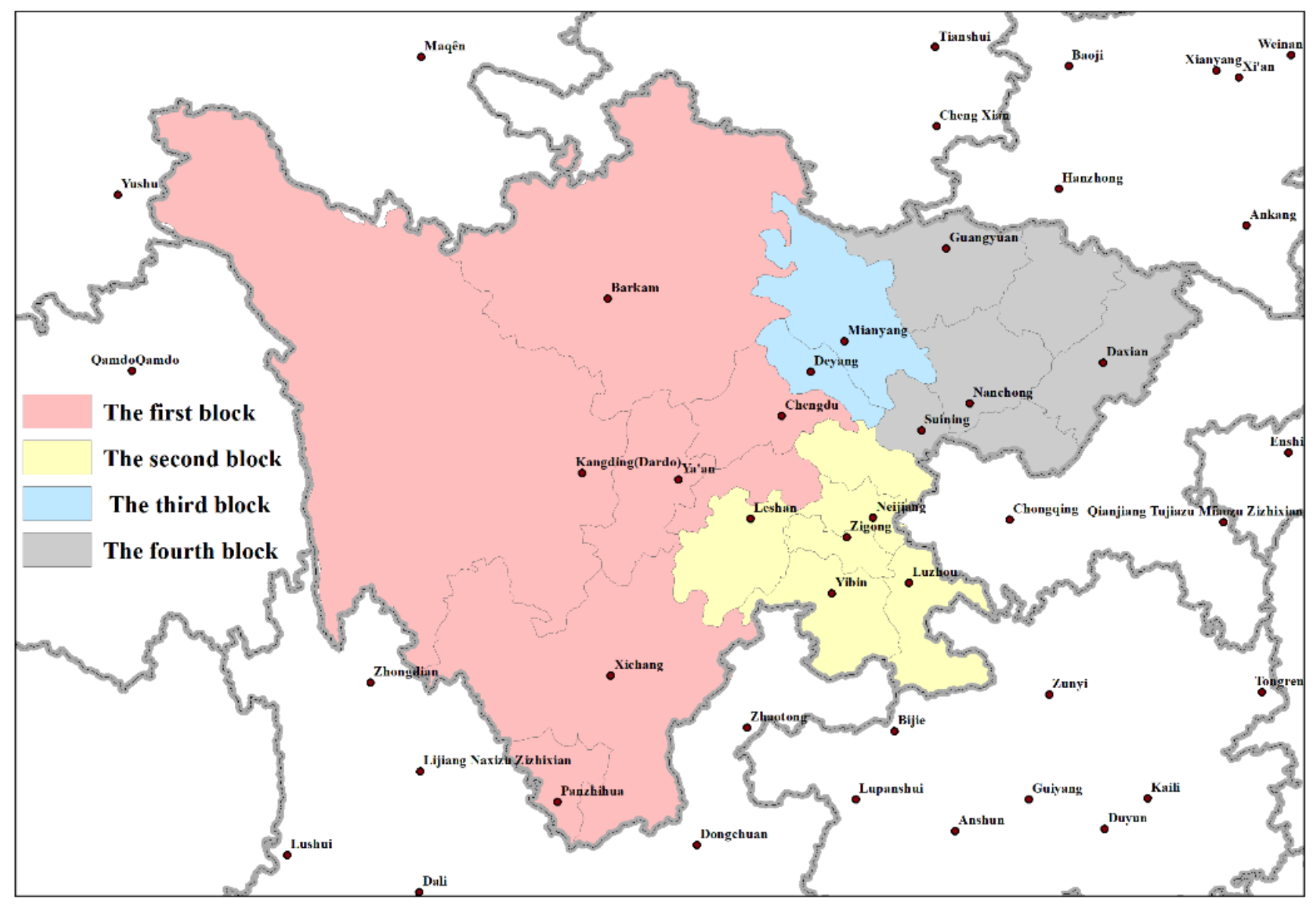

Figure 4

Four blocks 